\title{
BMJ Open Prevalence and associated factors of smoking in middle and high school students: a school-based cross-sectional study in Zhejiang Province, China
}

\author{
Meng Wang, Jie-Ming Zhong, Le Fang, Hao Wang
}

To cite: Wang M, Zhong J-M, Fang $L$, et al. Prevalence and associated factors of smoking in middle and high school students: a schoolbased cross-sectional study in Zhejiang Province, China. BMJ Open 2016;6:e010379. doi:10.1136/bmjopen-2015010379

- Prepublication history and additional material is available. To view please visit the journal (http://dx.doi.org/ 10.1136/bmjopen-2015010379).

Received 28 October 2015 Revised 16 December 2015 Accepted 23 December 2015

CrossMark

Zhejiang Provincial Center for Disease Control and Prevention, Hangzhou, China

Correspondence to Hao Wang; hwang@cdc.zj.cn

\section{ABSTRACT}

Objectives: To determine the prevalence and associated factors of smoking in a Chinese adolescent population.

Setting: A multistage, stratified cluster sampling technique was used in the present cross-sectional study conducted in Zhejiang Province of China. Based on socioeconomic status, school levels and geographical positions, 253 middle school classes, 122 academic school classes and 115 vocational high school classes located in 12 urban areas and 18 rural areas were chosen.

Participants: A total of 9617 middle school students, 5495 academic high school students and 4430 vocational high school students were recruited in this survey.

Primary and secondary outcome measures: Ever, current smoking status and associated factors were collected via a self-administered questionnaire. Logistic regression models were used to examine the associations between current smoking and the associated factors. ORs with their $95 \% \mathrm{Cls}$ were reported.

Results: Overall, the prevalence of ever-smokers and current smokers was $33.83 \%$ and $7.93 \%$, respectively. Focused on current smokers, significantly higher risks of adolescent smoking were observed in an older age group, boys, rural areas and vocational high school. Other significant factors were parents smoking, secondhand smoke exposure, parental divorce or separation, living with family, school performance and belief that smoking is harmful.

Conclusions: The prevalence of smoking was relatively high among Chinese adolescents in Zhejiang Province. Factors related to personal characteristics, family and school were associated with adolescent smoking.

\section{INTRODUCTION}

Tobacco use is one of the most serious public health threats worldwide. As the second leading contributor, tobacco smoking accounted for $6.3 \%$ of the global disease
Strengths and limitations of this study

- The present study had several strengths. This was a school-based study with relatively large sample size, high response rate and representative provincial samples from China. Besides, the study questionnaire involved a great number of factors, which might help us better understand how to prevent adolescent smoking.

- Our study also had some limitations. First, with its cross-sectional design, our study could not provide causal associations and further longitudinal researches are urgently needed. Second, in the current study, the smoking status of the participants was collected via self-administered questionnaires, which might underestimate the smoking prevalence among adolescents. Third, as the participants were selected in Zhejiang Province, our findings cannot be generalisable to the broader Chinese adolescent population.

burden in 2010. ${ }^{1}$ Considerable evidence has indicated that smoking is associated with many types of cancers and cardiovascular diseases. ${ }^{2}$ According to the $\mathrm{WHO}$, tobacco claims nearly six million lives annually, and this figure is expected to rise to more than eight million by the year $2030 .{ }^{3}$ With 301 million current smokers, China is facing the largest smoking problem on Earth, which poses a great public health challenge. ${ }^{4}$ In recent decades, high rates of smoking among adolescents have become a public health concern across the world, and China is no exception. A national survey focused on elementary and middle school students reported that the prevalence of ever-smokers and current smokers was $19.0 \%$ and $5.4 \%$, respectively. ${ }^{5}$ In addition, a meta-analysis of smoking prevalence among Chinese adolescents showed high levels of male smoking and a rapid increase in female smoking between 1981 and 2010. ${ }^{6}$ To develop more effective strategies against tobacco use 
among youths, it is crucial to study the associated factors of adolescent smoking. The causes of adolescent smoking are complex and multifactorial. Aside from the factors of sex, socioeconomic status and parental or friends smoking, ${ }^{7-9}$ with social and economic development, psychosocial factors within the family such as parental divorce or separation need more comprehensive research.

Although some research regarding smoking has been conducted in China, studies on the prevalence of adolescent smoking and associated factors are still lacking. Therefore, the primary objective of this study is to estimate the prevalence of smoking among Chinese middle and high school students, and to explore the associated factors of adolescent smoking.

\section{MATERIALS AND METHODS \\ Participants}

The present school-based cross-sectional study was conducted in Zhejiang Province of China in 2012. Middle and high school students were recruited to investigate the prevalence and associated factors of smoking among them. In China, at the age of 6 years, children enter the first grade of primary education, which lasts 6 years. After primary education, they all enter middle school at 12 years of age for 3 years of education. Then, after an entrance examination, they enter high school (including academic and vocational) for another 3 years of education. When drawing the samples, a multistage, stratified cluster sampling technique was used. In the first stage, 30 counties, including 12 urban areas and 18 rural areas, were sampled from all 90 counties of Zhejiang Province on the basis of socioeconomic status. The 12 urban areas included Shangcheng, Xiacheng, Haishu, Lucheng, Putuo, Kecheng, Wuxing, Nanhu, Wucheng, Yuecheng, Jiaojiang and Liandu. The 18 rural areas included Fuyang, Jiande, Yuyao, Fenghua, Jiashan, Tongxiang, Yueqing, Pingyang, Xianju, Wenling, Shangyu, Xinchang, Wuyi, Dongyang, Anji, Kaihua, Suichang and Yunhe. Then, all schools in selected counties were stratified according to their levels (middle school, academic and vocational high school) and geographical positions (from west to east, from north to south). In the second stage, based on the number of students in each level of school, samples of classes were chosen in each level of school (253 middle school classes, 122 academic school classes and 115 vocational high school classes). Finally, students in all selected classes were invited to participate in the survey.

\section{Questionnaire}

The self-administered questionnaire was developed based on the US 1991-2015 Youth Risk Behavior Surveillance System (YRBSS) and Global School-based Student Health Survey (GSHS) supported by the WHO. The questionnaire was reviewed, checked and approved by experts, and revised after a pilot study. The questionnaire covered information on demographic characteristics, health status and quality of life, physical activity, cigarette smoking and alcohol use, internet use, diet, violence, injuries and sexual behaviours. Without teachers present, students independently filled in the anonymous questionnaire in the classroom. After completion, the questionnaires were collected on the spot by the researchers. To make all participation voluntary, parents and school officials were sent a written letter to inform them that a study was to be conducted to examine issues relevant to adolescent health, and given the option to refuse the students' participation in the study. Besides, all the researchers were strictly trained to protect the students' privacy and ensure the confidentiality of personal data. In particular, our study abided by the 'Declaration of Helsinki'

\section{Definition of study variables}

Participants' smoking behaviours were assessed in the questionnaire according to the following queries: (1) 'Have you ever tried cigarette smoking, even one or two puffs?' (Yes or No); (2) 'During the past 30 days, on how many days did you smoke cigarettes?' $(0,1-2,3-5,6-9$, $10-19,20-29,30$ days). Ever-smokers were identified if they answered that they had tried cigarette smoking, even one or two puffs. Participants were considered as current smokers if they answered that they had smoked at least 1 day during the past 30 days.

The explanatory variables were also taken into consideration in this study. They were age range $(\leq 13,14,15$, $\geq 16$ years), gender (girls, boys), location of school (urban, rural), father's education level $(<$ middle school graduate, middle school graduate, $>$ middle school graduate), mother's education level $(<$ middle school graduate, middle school graduate, $>$ middle school graduate), only child (yes, no), school level (middle school, academic high school, vocational high school), parental marriage status (married, divorced/widowed/separated), parents smoking (no, one parent, both), belief that smoking is harmful (yes, no), secondhand smoke exposure (yes, no), school performance (below average, average, excellent), and living with family (yes, no).

\section{Statistical analysis}

Descriptive statistics were used to estimate the prevalence of ever-smokers and current smokers among middle and high school students. To explore the associated factors of adolescents smoking, logistic regression analyses were conducted using two steps in sequence. First, univariate logistic regression analyses were carried out to preliminarily determine which of the potential factors (in tables 1 and 2) were associated with current smoking among adolescents. Second, a multivariate logistic regression model was constructed by adding all the significant factors from the above univariate logistic regression analyses. The effect values were reported by OR with their $95 \%$ CIs. All analyses were performed 
Table 1 Univariate analysis on the associations between demographic characteristics and the risk of adolescent current smoking

\begin{tabular}{|c|c|c|c|c|}
\hline Characteristics & Smokers ( $\mathrm{N}=1549 ; \%)$ & Non-smokers ( $\mathrm{N}=17$ 993; \%) & OR & $95 \% \mathrm{Cl}$ \\
\hline \multicolumn{5}{|l|}{ Age range (years) } \\
\hline$\leq 13$ & $107(2.74)$ & $3797(97.26)$ & Ref. & \\
\hline$\overline{14}-$ & $144(4.74)$ & $2894(95.26)$ & 1.77 & 1.37 to 2.28 \\
\hline $15-$ & $276(8.36)$ & 3026 (91.64) & 3.24 & 2.58 to 4.07 \\
\hline$\geq 16$ & $1022(10.99)$ & $8276(89.01)$ & 4.38 & 3.58 to 5.37 \\
\hline \multicolumn{5}{|l|}{ Gender } \\
\hline Girls & $242(2.46)$ & $9577(97.54)$ & Ref. & \\
\hline Boys & $1307(13.44)$ & $8416(86.56)$ & 6.15 & 5.34 to 7.07 \\
\hline \multicolumn{5}{|l|}{ Location of school } \\
\hline Urban & $488(6.64)$ & $6858(93.36)$ & Ref. & \\
\hline Rural & $1061(8.70)$ & $11135(91.30)$ & 1.34 & 1.20 to 1.50 \\
\hline \multicolumn{5}{|l|}{ Father's education level } \\
\hline$<$ Middle school graduate & $382(8.87)$ & 3926 (91.13) & Ref. & \\
\hline Middle school graduate & $723(8.46)$ & 7827 (91.54) & 0.95 & 0.83 to 1.08 \\
\hline >Middle school graduate & 444 (7.07) & 6240 (92.93) & 0.73 & 0.63 to 0.84 \\
\hline \multicolumn{5}{|l|}{ Mother's education level } \\
\hline$<$ Middle school graduate & $531(8.77)$ & $5522(91.23)$ & Ref. & \\
\hline Middle school graduate & 665 (8.28) & 7365 (91.72) & 0.94 & 0.83 to 1.06 \\
\hline$>$ Middle school graduate & $353(6.47)$ & 5106 (93.53) & 0.72 & 0.63 to 0.83 \\
\hline \multicolumn{5}{|l|}{ Only child } \\
\hline Yes & $850(8.25)$ & $9450(91.75)$ & Ref. & \\
\hline No & 699 (7.56) & 8543 (92.44) & 0.91 & 0.82 to 1.01 \\
\hline \multicolumn{5}{|l|}{ School level } \\
\hline Middle school & $442(4.60)$ & $9175(95.40)$ & Ref. & \\
\hline Academic high school & $355(6.46)$ & 5140 (93.54) & 1.43 & 1.24 to 1.66 \\
\hline Vocational high school & $752(16.98)$ & 3678 (83.02) & 4.24 & 3.75 to 4.80 \\
\hline \multicolumn{5}{|l|}{ Parental marriage status } \\
\hline Married & $1377(7.79)$ & $16303(92.21)$ & Ref. & \\
\hline Divorced/widowed/separated & $172(9.24)$ & 1690 (90.76) & 1.21 & 1.02 to 1.42 \\
\hline
\end{tabular}

using SAS statistical package (V.9.2, SAS Institute, Inc, Cary, North Carolina, USA).

\section{RESULTS}

For this survey, 21110 students were chosen randomly and 20589 agreed to participate, yielding a response rate of $97.53 \%$. Among the 20589 completed questionnaires, 108 missing substantial responses and 939 from migrants were excluded from the analysis. In total, this study included 19542 middle and high school students recruited from 30 counties in Zhejiang Province of China. The mean age was $15.35 \pm 1.84$ years. Among them, there were $9819(50.25 \%)$ girls and 9723 $(49.75 \%)$ boys; and $9617(49.21 \%)$ middle and 9925 $(50.79 \%)$ high school students. Overall, $33.83 \%(95 \%$ CI $33.17 \%$ to $34.51 \%$ ) of the participants had eversmoked, of whom, boys and girls accounted for $44.79 \%$ (95\% CI $43.80 \%$ to $45.78 \%)$ and $22.99 \%(95 \%$ CI $22.16 \%$ to $23.82 \%$ ), respectively. Only $7.93 \%$ (95\% CI $7.52 \%$ to $8.28 \%$ ) of the participants were current smokers and the prevalence was much higher in boys $(13.44 \%, 95 \%$ CI $12.76 \%$ to $14.12 \%)$ than in girls (2.42\%, $95 \%$ CI $2.12 \%$ to $2.72 \%)$.

The following analyses focused only on current smokers. Table 1 shows the risks of current smoking among adolescents with different demographic characteristics: age (16years or more vs < 13 years; $\mathrm{OR}=4.38,95 \%$ CI 3.58 to 5.37 ), gender (boys vs girls; $\mathrm{OR}=6.15,95 \%$ CI 5.34 to 7.07 ), location of school (rural vs urban; $\mathrm{OR}=1.34,95 \%$ CI 1.20 to 1.50 ), school level (vocational high school vs middle school; $\mathrm{OR}=4.24,95 \%$ CI 3.75 to 4.80 ), father's education level (more than middle school graduate vs less than middle school graduate; $\mathrm{OR}=0.73,95 \%$ CI 0.63 to 0.84$)$, mother's education level (more than middle school graduate vs less than middle school graduate; OR $=0.72,95 \%$ CI 0.63 to 0.83 ) and parental marriage status (divorced/widowed/ separated vs married; OR=1.21, 95\% CI 1.02 to 1.42 ).

Table 2 shows the analysis on the associations between related factors and the risk of adolescent current smoking. There were significant associations between smoking and the following factors: parents smoking (both vs none; $\mathrm{OR}=2.61,95 \%$ CI 1.79 to 3.81 ), belief that smoking is harmful (yes vs no; $\mathrm{OR}=0.29$, 95\% CI 0.22 to 0.40 ), secondhand smoke exposure (yes vs no; $\mathrm{OR}=2.22,95 \%$ CI 1.99 to 2.48 ), school performance (excellent vs below average; $\mathrm{OR}=0.25,95 \%$ CI 0.21 to 0.29 ) and living with family (yes vs no; $\mathrm{OR}=0.64,95 \%$ CI 0.57 to 0.71 ).

Table 3 displays the results of multivariate analysis including all the significant factors on current 
Table 2 Univariate analysis on the associations between related factors and the risk of adolescent current smoking

\begin{tabular}{|c|c|c|c|c|}
\hline Factors & Smokers (N=1549; \%) & Non-smokers (N=17 993; \%) & OR & $95 \% \mathrm{Cl}$ \\
\hline \multicolumn{5}{|l|}{ Parents smoking } \\
\hline No & $433(6.08)$ & 6688 (93.92) & Ref. & \\
\hline One parent & $1082(8.88)$ & $11104(91.12)$ & 1.51 & 1.34 to 1.69 \\
\hline Both & 34 (14.47) & $201(85.53)$ & 2.61 & 1.79 to 3.81 \\
\hline \multicolumn{5}{|c|}{ Belief that smoking is harmful } \\
\hline No & 57 (22.27) & 199 (77.73) & Ref. & \\
\hline Yes & $1492(7.74)$ & 17794 (92.26) & 0.29 & 0.22 to 0.40 \\
\hline \multicolumn{5}{|c|}{ Secondhand smoke exposure } \\
\hline No & 499 (5.12) & $9242(94.88)$ & Ref. & \\
\hline Yes & $1050(10.71)$ & $8751(89.29)$ & 2.22 & 1.99 to 2.48 \\
\hline \multicolumn{5}{|c|}{ School performance } \\
\hline Below average & $759(14.25)$ & $4568(85.75)$ & Ref. & \\
\hline Average & $617(6.28)$ & 9206 (93.72) & 0.40 & 0.36 to 0.45 \\
\hline Excellent & $173(3.94)$ & $4219(96.06)$ & 0.25 & 0.21 to 0.29 \\
\hline \multicolumn{5}{|l|}{ Living with family } \\
\hline No & $990(9.39)$ & 9555 (90.61) & Ref. & \\
\hline Yes & $559(6.21)$ & 8438 (93.79) & 0.64 & 0.57 to 0.71 \\
\hline
\end{tabular}

Table 3 Multivariate analysis on the associations between related factors and the risk of adolescent current smoking

\begin{tabular}{|c|c|c|c|c|}
\hline Factors & Smokers (N=1549; \%) & Non-smokers (N=17 993; \%) & $\mathbf{O R}^{*}$ & $95 \% \mathrm{Cl}$ \\
\hline \multicolumn{5}{|l|}{ Age range (years) } \\
\hline$\leq 13$ & $107(2.74)$ & $3797(97.26)$ & Ref. & \\
\hline $14-$ & $144(4.74)$ & $2894(95.26)$ & 1.69 & 1.30 to 2.19 \\
\hline $15-$ & $276(8.36)$ & 3026 (91.64) & 2.50 & 1.95 to 3.20 \\
\hline$\geq 16$ & $1022(10.99)$ & $8276(89.01)$ & 2.54 & 1.88 to 3.44 \\
\hline \multicolumn{5}{|l|}{ Gender } \\
\hline Girls & $242(2.46)$ & $9577(97.54)$ & Ref. & \\
\hline Boys & $1307(13.44)$ & $8416(86.56)$ & 6.85 & 5.92 to 7.92 \\
\hline \multicolumn{5}{|l|}{ Location of school } \\
\hline Urban & $488(6.64)$ & $6858(93.36)$ & Ref. & \\
\hline Rural & $1061(8.70)$ & $11135(91.30)$ & 1.24 & 1.10 to 1.41 \\
\hline \multicolumn{5}{|l|}{ School level } \\
\hline Middle school & $442(4.60)$ & $9175(95.40)$ & Ref. & \\
\hline Academic high school & $355(6.46)$ & 5140 (93.54) & 0.99 & 0.77 to 1.26 \\
\hline Vocational high school & $752(16.98)$ & $3678(83.02)$ & 3.14 & 2.49 to 3.98 \\
\hline \multicolumn{5}{|l|}{ Parental marriage status } \\
\hline Married & 1377 (7.79) & $16303(92.21)$ & Ref. & \\
\hline Divorced/widowed/separated & $172(9.24)$ & $1690(90.76)$ & 1.33 & 1.11 to 1.59 \\
\hline \multicolumn{5}{|l|}{ Parents smoking } \\
\hline No & $433(6.08)$ & 6688 (93.92) & Ref. & \\
\hline One parent & $1082(8.88)$ & $11104(91.12)$ & 1.24 & 1.09 to 1.40 \\
\hline Both & 34 (14.47) & $201(85.53)$ & 2.05 & 1.33 to 3.15 \\
\hline \multicolumn{5}{|l|}{ Belief that smoking is harmful } \\
\hline No & $57(22.27)$ & 199 (77.73) & Ref. & \\
\hline Yes & $1492(7.74)$ & 17794 (92.26) & 0.31 & 0.22 to 0.44 \\
\hline \multicolumn{5}{|l|}{ Secondhand smoke exposure } \\
\hline No & $499(5.12)$ & $9242(94.88)$ & Ref. & \\
\hline Yes & $1050(10.71)$ & $8751(89.29)$ & 2.05 & 1.82 to 2.31 \\
\hline \multicolumn{5}{|l|}{ School performance } \\
\hline Below average & 759 (14.25) & $4568(85.75)$ & Ref. & \\
\hline Average & $617(6.28)$ & 9206 (93.72) & 0.44 & 0.39 to 0.50 \\
\hline Excellent & $173(3.94)$ & $4219(96.06)$ & 0.28 & 0.24 to 0.34 \\
\hline \multicolumn{5}{|l|}{ Living with family } \\
\hline No & $990(9.39)$ & $9555(90.61)$ & Ref. & \\
\hline Yes & $559(6.21)$ & 8438 (93.79) & 0.78 & 0.69 to 0.88 \\
\hline
\end{tabular}


adolescents smoking. After adjusting for various factors, listed in tables 1 and 2, significantly higher risk in older age group and lower risk in adolescents with excellent school performance were observed. For three age groups (14-15, 15-16, $\geq 16$ years), the ORs ranged from 1.69 to 2.54 and the $95 \%$ CI did not include the null. Compared to adolescents with below average school performance, the ORs of adolescents with average and excellent school performance ranged from 0.28 to 0.44 , and the $95 \%$ CI did not include the null. Compared to girls and urban area, boys and students in rural areas were, respectively, 6.85 ( $\mathrm{OR}=6.85,95 \%$ CI 5.92 to 7.92$)$ and $1.24(\mathrm{OR}=1.24,95 \%$ CI 1.10 to 1.41$)$ times more likely to smoke currently. School level was positively associated with adolescent current smoking and the risk was 3.14 ( $\mathrm{OR}=3.14,95 \%$ CI 2.49 to 3.98$)$ among vocational high school students. A significant risk of adolescents currently smoking was also found associated with parents smoking. The risk was $1.24(\mathrm{OR}=1.24,95 \% \mathrm{CI}$ 1.09 to 1.40) for adolescents having one parent smoking and $2.05(\mathrm{OR}=2.05,95 \%$ CI 1.33 to 3.15$)$ for those having both parents smoking. Our results showed that adolescents with adverse parental marriage status $(\mathrm{OR}=1.33,95 \%$ CI 1.11 to 1.59$)$ and secondhand smoke exposure $(\mathrm{OR}=2.05,95 \%$ CI 1.82 to 2.31$)$ had a higher risk of current smoking. In addition, adolescents who believed the harmful effects of smoking ( $\mathrm{OR}=0.31,95 \%$ CI 0.22 to 0.44 ) and lived with family (OR=0.78, $95 \%$ CI 0.69 to 0.88 ) had a lower risk of current smoking.

\section{DISCUSSION}

On the basis of 19542 middle and high school students, this study was performed to estimate the prevalence of smoking and explore the associated factors in a Chinese adolescent population. In this survey, the overall prevalence of current smokers was $7.93 \%$ (including $13.44 \%$ of boys and $2.46 \%$ of girls). According to the newly released data from the 2014 Global Youth Tobacco Survey (GYTS), $5.9 \%$ of students (9.9\% of boys and $1.6 \%$ of girls) aged 13-15 years were current cigarette smokers in China, ${ }^{10}$ results that were lower than ours. Some research has been carried out in other countries. For example, the Florida Youth Tobacco Survey (FYTS) 2014 indicated that $8.7 \%$ of high school and $2.9 \%$ of middle school students had smoked cigarettes in the past month, ${ }^{11}$ which were higher than our results of academic high school $(6.46 \%)$ and lower than that of middle school students $(4.60 \%)$, respectively. Besides, according to a large cross-sectional survey conducted in London in 2011-2012, a current smoking prevalence of $3.4 \%$ was reported among students in secondary schools. ${ }^{12}$ The smoking prevalence among adolescents varied in these studies, which might be due to the different samples, smoking definition and social circumstances. In 1998, a school-based survey conducted in Zhejiang Province reported that only $0.3 \%$ in total, and no girls, in Chinese secondary school students were regular smokers (defined as at least 1 cigarette per week). ${ }^{7}$ Although the samples and smoking definition were different, the comparison with our prevalence data revealed a fast growing number of adolescent smokers in China since the 1990s.

Associated factors of adolescent current smoking have been examined in this study and particular attention should be focused on certain groups. In the present study, significantly increased risks of current smoking were observed in an older age group, boys, rural areas and vocational high school, which was consistent with previous researches showing the role of personal characteristics in adolescents' smoking initiation and continuation. ${ }^{8} 13$ Family influence has been extensively analysed and a wide range of family factors were reported to be associated with adolescent smoking. Parental smoking has been considered a strong predictor of adolescent smoking. ${ }^{14-16}$ We found consistent evidence that parental smoking significantly impacted their children's current smoking behaviour. Specifically, adolescents having both parents smoking are at a greater current smoking risk than those having only one parent smoking (2.05 vs 1.24). Besides, studies further indicated that adolescents were more likely to smoke when the mothers smoked, and the mothers' smoking influenced girls' more than boys' smoking. ${ }^{17}{ }^{18}$ Secondhand smoke is a significant public health problem among never-smoking adolescents. ${ }^{19}$ However, the independent influence of secondhand smoke on adolescent smoking has scarcely been explored. In this study, we found a higher risk of current smoking among adolescents exposed to secondhand smoke $(\mathrm{OR}=2.05$, $95 \%$ CI 1.82 to 2.31 ), which was equal to the effect of having both parents smoking. Many studies have documented evidence that adolescents from divorced or separated families were more likely to smoke. ${ }^{20}{ }^{21}$ Our observations indicated a consistent positive association between parental divorce or separation and adolescents' current smoking behaviour. As for how parental divorce influences adolescent smoking, family conflicts and family disharmony might be important contributors; the relationship with adolescents' smoking behaviours has been explored by various studies. ${ }^{14} 22{ }^{23}$ A lower risk of current smoking was observed among adolescents who lived with family ( $\mathrm{OR}=0.78,95 \%$ CI 0.69 to 0.88 ), which reinforced a positive role of parental monitoring in preventing adolescent smoking. ${ }^{24}$ Except for family influence, school-related factors, especially academic achievement, was also identified as a predicting factor of adolescent smoking. ${ }^{25} 26$ In our study, good performance (average, excellent) at school was found to be consistently associated with lower risk of adolescent current smoking. Finally, belief that smoking is harmful was reported to be negatively associated with the risk of smoking among adolescents. In the current study, a lower risk of current smoking was observed among adolescents who believed smoking is harmful, which confirmed the results of previous studies. ${ }^{27} 28$ 
In conclusion, the prevalence of smoking was relatively high among Chinese adolescents in Zhejiang Province. Personal characteristics played a role in influencing adolescents' smoking behaviour. Parental smoking, secondhand smoke exposure, parental divorce, living with family, school performance and belief that smoking is harmful were also associated with adolescent smoking. In developing school-based antismoking policy and programmes, particular attention should be focused on adolescents with the factors aforementioned.

Acknowledgements The authors would like to thank all the students, parents, teachers and local officials for their participation, assistance and co-operation.

Contributors MW designed the study, and collected and analysed the data with HW and LF. Professor J-MZ gave much advice and directions in study design and preparing of the manuscript. All the authors have read and approved the final submitted version.

Funding This study was supported by Zhejiang Provincial Major Special Project of Science and Technology (number 2011C13032-1).

Competing interests None declared

Ethics approval Ethnics Committee of Zhejiang Provincial Center for Disease Control and Prevention.

Provenance and peer review Not commissioned; externally peer reviewed.

Data sharing statement No additional data are available.

Open Access This is an Open Access article distributed in accordance with the Creative Commons Attribution Non Commercial (CC BY-NC 4.0) license, which permits others to distribute, remix, adapt, build upon this work noncommercially, and license their derivative works on different terms, provided the original work is properly cited and the use is non-commercial. See: http:// creativecommons.org/licenses/by-nc/4.0/

\section{REFERENCES}

1. Lim SS, Vos T, Flaxman AD, et al. A comparative risk assessment of burden of disease and injury attributable to 67 risk factors and risk factor clusters in 21 regions, 1990-2010: a systematic analysis for the Global Burden of Disease Study 2010. Lancet 2012;380:2224-60.

2. Beaglehole $\mathrm{R}$, Bonita R, Horton R, et al. Priority actions for the non-communicable disease crisis. Lancet 2011;377:1438-47.

3. World Health Organization. Tobacco. 2015. http://www.who.int/ mediacentre/factsheets/fs339/en/ (16 June 2015).

4. Li Q, Hsia J, Yang G. Prevalence of smoking in China in 2010 N Engl J Med 2011;364:2469-70.

5. Zhang X, Li Y, Zhang Q, et al. Smoking and its risk factors in Chinese elementary and middle school students: a nationally representative sample study. Addict Behav 2014;39:837-41.

6. Han J, Chen X. A meta-analysis of cigarette smoking prevalence among adolescents in China: 1981-2010. Int J Environ Res Public Health 2015;12:4617-30.

7. Hesketh T, Ding QJ, Tomkins A. Smoking among youths in China. Am J Public Health 2001;91:1653-5.
8. Anderson Johnson C, Palmer PH, Chou CP, et al. Tobacco use among youth and adults in Mainland China: the China Seven Cities Study. Public Health 2006;120:1156-69.

9. Hiscock R, Bauld L, Amos A, et al. Socioeconomic status and smoking: a review. Ann N Y Acad Sci 2012;1248:107-23.

10. World Health Organization. China Global Youth Tobacco Survey. 2014 http://www.wpro.who.int/china/gyts_china_fs_en_20140528. pdf?ua=1\&ua=1 (16 June 2015).

11. Porter L, Duke J, Hennon M, et al. Electronic cigarette and traditional cigarette use among middle and high school students in Florida, 2011-2014. PLoS ONE 2015;10:e0124385.

12. Jawad M, Wilson A, Lee JT, et al. Prevalence and predictors of water pipe and cigarette smoking among secondary school students in London. Nicotine Tob Res 2013;15:2069-75.

13. Tang SM, Loke AY. Smoking initiation and personal characteristics of secondary students in Hong Kong. J Adv Nurs 2013;69:1595-606.

14. Xie B, Palmer P, Li Y, et al. Developmental trajectories of cigarette use and associations with multilayered risk factors among Chinese adolescents. Nicotine Tob Res 2013;15:1673-81.

15. El-Amin Sel-T, Nwaru BI, Ginawi I, et al. The role of parents, friends and teachers in adolescents' cigarette smoking and tombak dipping in Sudan. Tob Control 2011;20:94-9.

16. Mashita RJ, Themane MJ, Monyeki KD, et al. Current smoking behaviour among rural South African children: Ellisras Longitudinal Study. BMC Pediatr 2011;11:58.

17. Leonardi-Bee J, Jere ML, Britton J. Exposure to parental and sibling smoking and the risk of smoking uptake in childhood and adolescence: a systematic review and meta-analysis. Thorax 2011;66:847-55.

18. Sullivan KM, Bottorff J, Reid C. Does mother's smoking influence girls' smoking more than boys' smoking? A 20-year review of the literature using a sex- and gender-based analysis. Subst Use Misuse 2011;46:656-68.

19. Veeranki SP, Mamudu HM, Zheng S, et al. Secondhand smoke exposure among never-smoking youth in 168 countries. J Adolesc Health 2015;56:167-73.

20. Kestilä L, Koskinen S, Martelin T, et al. Influence of parental education, childhood adversities, and current living conditions on daily smoking in early adulthood. Eur J Public Health 2006;16:617-26.

21. Anda RF, Croft JB, Felitti VJ, et al. Adverse childhood experiences and smoking during adolescence and adulthood. JAMA 1999;282:1652-8.

22. Kristjansson AL, Sigfusdottir ID, Allegrante JP, et al. Parental divorce and adolescent cigarette smoking and alcohol use: assessing the importance of family conflict. Acta Paediatr 2009;98:537-42.

23. Moor I, Rathmann K, Lenzi M, et al. Socioeconomic inequalities in adolescent smoking across 35 countries: a multilevel analysis of the role of family, school and peers. Eur J Public Health 2015;25:457-63.

24. Simons-Morton BG. Prospective analysis of peer and parent influences on smoking initiation among early adolescents. Prev $\mathrm{Sci}$ 2002;3:275-83.

25. Khuder SA, Price JH, Jordan T, et al. Cigarette smoking among adolescents in Northwest Ohio: correlates of prevalence and age at onset. Int J Environ Res Public Health 2008;5:278-89.

26. Gaffar AM, Alsanosy RM, Mahfouz MS. Sociodemographic factors associated with tobacco smoking among intermediate and secondary school students in Jazan Region of Saudi Arabia. Subst Abus 2013;34:381-8.

27. Rudatsikira E, Muula AS, Siziya S. Current use of smokeless tobacco among adolescents in the Republic of Congo. BMC Public Health 2010;10:16.

28. Al-Zalabani A, Kasim K. Prevalence and predictors of adolescents cigarette smoking in Madinah, Saudi Arabia: a school-based cross-sectional study. BMC Public Health 2015;15:17. 